\title{
Combined external pelvic chemoradiotherapy and image-guided adaptive brachytherapy in treatment of advanced cervical carcinoma: experience from a single institution
}

\author{
Sigrid Möller, MD', Louise Bohr Mordhorst, MD, PhD', Ruth Sanchez Hermansson, MD', Leif Karlsson, Phlic², \\ Ulf Granlund, MSc², Cecilia Riemarsma, MD³, Bengt Sorbe, MD, PhD 14 \\ 'Department of Oncology, University Hospital, Örebro, Sweden, ${ }^{2}$ Department of Radiation Physics, University Hospital, Örebro, Sweden, \\ ${ }^{3}$ Department of Obstetrics and Gynecology, Central Hospital, Karlstad, Sweden, ${ }^{4}$ Faculty of Medicine and Health, Örebro University, Sweden
}

\begin{abstract}
Purpose: External pelvic chemoradiotherapy and image-guided adaptive brachytherapy (IGABT) were studied in advanced cervical carcinomas. Treatment modalities were defined and related to outcomes and side effects.

Material and methods: From a single cancer center, 138 patients with advanced cervical cancer were recruited. All patients were treated with external radiotherapy and IGABT. A dosimetric study was performed and related to treatment outcome and side effects. Toxicity of the organs at risk was evaluated by the CTCAE-grading system.

Results: The median follow-up was 44 months. More than $60 \%$ of the tumors were FIGO stage IIB-IIIB and $82 \%$ were squamous cell carcinomas. Largest tumor size (width) was in mean $41 \mathrm{~mm}$ and $27 \%$ had lymph node spread. The mean total external dose was $51 \mathrm{~Gy}$, and the mean total dose to the high-risk clinical target volume (HRCTV) was 88 Gy. In 130 patients (94\%), weekly cisplatin was given in 4-6 cycles. The median number of brachytherapy fractions was four, and in 86 patients, interstitial needles were applied. The primary local control was $97 \%$ and $94 \%$ after four local recurrences. The overall pelvic control was $89 \%$. The overall recurrence rate was $25 \%$ and distant metastases rate was $22 \%$. The overall 5-year survival rate was $65 \%$ and cancer-specific survival rate was $69 \%$. Prognostic factors were FIGO stage and total brachytherapy dose $\left(D_{90}\right)$ to HRCTV. Late serious toxicity of the bladder and intestine were rare, occurring in only $3 \%$ of patients.

Conclusions: The local and pelvic control rates were excellent in this series. The IGABT was an important part of the treatment schedule and could probably not be replaced by increasing the external pelvic dose. Adenocarcinomas seemed to benefit from the addition of interstitial needles. Late serious toxicity was rare.
\end{abstract}

J Contemp Brachytherapy 2020; 12, 4: 356-366

DOI: https://doi.org/10.5114/jcb.2020.98116

Key words: cervix cancer, image-guided brachytherapy, chemoradiotherapy, local tumor control, survival, toxicity.

\section{Purpose}

Cervical cancer ranges as the fourth most frequently diagnosed cancer and the fourth leading cause of death among women worldwide as presented by the International Agency for Research on Cancer 2018 in GLOBOCAN estimates [1]. Persistent human papillomavirus (HPV) infection is one of the most important risk factors for developing cervical carcinomas, and the virus is present in the vast majority of tumors [2]. According to the World Health Organization, the histological subtypes are divided into three categories, including the most common squamous cell carcinomas, which constitute approximate- ly $70-80 \%$ of cases, adenocarcinomas with $20-25 \%$ of cases, and other epithelial tumors [2].

Cervical cancer incidence has decreased over the last decades, mainly due to screening programs. An estimation from four Nordic countries, with Sweden included, suggested that screening may have prevented $41-49 \%$ of the expected cases of cervical cancer [3]. Screening programs allow to detect premalignant lesions, and the global variation in cervical cancer in part reflects the variation of possibility for women to take part in screening programs [2]. Moreover, recently introduced HPV vaccines may further reduce cervical cancer incidence [2].

Address for correspondence: Prof. Bengt Sorbe, MD, PhD, Department of Oncology, University Hospital, Received: 12.01 .2020 SE-701 85 Örebro, Sweden, phone: +46 706202178, 凶 e-mail: b.sorbe@telia.com 
Among prognostic factors, FIGO stage is one of the most important [2]. For cervical cancer in FIGO stage I-IIA, surgery is the primary treatment. For cervical cancer categorized as FIGO stage IB2-IVA considered as locally advanced disease, the current standard of care is a combination of radio- and chemotherapy with brachytherapy. Cisplatin is frequently applied during chemotherapy, given once weekly in the dose of $40 \mathrm{mg} / \mathrm{m}^{2}$ [2]. An addition of concomitant chemotherapy has increased the survival rate $[4,5,6]$.

Regarding radiotherapy, a combination of external beam radiotherapy and brachytherapy is generally used. The introduction of brachytherapy has contributed to improved management of cervical carcinomas, allowing a higher concentrated dose delivered to the tumor without harming adjacent organs at risk [7].

Intracavitary brachytherapy in combination with external beam therapy and concurrent chemotherapy have exceptionally good results regarding local control [8]. The combination of intracavitary brachytherapy and external beam therapy had been previously shown to increase the overall survival rate as compared to external beam therapy in combination with external boost therapy, especially for tumors classified as FIGO stage II [9].

As far as radiotherapy side effects are considered, early reactions seem to be less prevalent among patients treated with brachytherapy as compared to those treated with external boost. Regarding late toxicity, it was previously shown that the frequency was similar [9].

While comparing image-guided adaptive brachytherapy (IGABT) given with only intracavitary applicator with a combination of intracavitary and interstitial applicators, bladder and bowel side effects were similar, but late vaginal side effects grade 2 or higher were slightly more prevalent among patients who had received brachytherapy with intracavitary and interstitial applications [10].

Among predictive factors for radiation side effects, there is an association between the width and lateral extent of external pelvic radiotherapy fields and early side effects, especially symptoms from the bladder and bowel. For late side effects, the same predictive factors related to external radiotherapy were found; however, it was shown that prior abdominal surgery increased the risk of late side effects, whereas concomitant cisplatin did not increase the risk of side effects [11].

The aim of our study was to present the treatment outcome (local and pelvic control, and survival) and bladder, bowel, vagina, and bone side effects in patients with cervical cancer treated with radiochemotherapy, including modern IGABT brachytherapy in a single-institution setting.

\section{Material and methods \\ Patients and tumors}

A consecutive series of 147 cervical carcinomas treated with combined external radiotherapy and intracavitary brachytherapy form January 1, 2010 and December 31, 2016, were included in this retrospective series (Table 1). Patients treated with surgery or external radiotherapy only were not included into this study. For 138 patients, all clinical data were available for analysis, together with dosimetric data from IGABT. In 86 patients, interstitial needles were used as a part of brachytherapy (IGABT). In 130 patients $(94.2 \%)$, concurrent chemotherapy (weekly cisplatin $40 \mathrm{mg} / \mathrm{m}^{2}$ ) was administered during radiation therapy. In 21 patients $(15.2 \%)$, neoadjuvant

Table 1. Patient and tumor characteristics

\begin{tabular}{|c|c|}
\hline Factor & No. of patients, $n(\%)$ \\
\hline Median age (years) & 53.0 (range, 23-89) \\
\hline Prior diseases & $80(58.0)$ \\
\hline Prior abdominal surgery & $38(27.5)$ \\
\hline \multicolumn{2}{|l|}{ FIGO stage } \\
\hline IB & $21(15.2)$ \\
\hline$\| A$ & $17(12.3)$ \\
\hline $\mathrm{IIB}$ & $66(47.8)$ \\
\hline IIIA & $2(1.4)$ \\
\hline IIIB & 19 (13.8) \\
\hline IVA & $9(6.5)$ \\
\hline IVB & $4(2.9)$ \\
\hline \multicolumn{2}{|l|}{ Histology } \\
\hline Squamous cell carcinoma & $113(81.9)$ \\
\hline Adenocarcinoma & 19 (13.8) \\
\hline Adenosquamous cell carcinoma & $3(2.2)$ \\
\hline Other & $3(2.2)$ \\
\hline \multicolumn{2}{|l|}{ Grade } \\
\hline Well-differentiated (grade 1) & $12(8.7)$ \\
\hline $\begin{array}{l}\text { Moderately well-differentiated } \\
\text { (grade 2) }\end{array}$ & $42(30.4)$ \\
\hline Poorly differentiated (grade 3) & $70(50.7)$ \\
\hline Not graded & $14(10.1)$ \\
\hline \multicolumn{2}{|l|}{ Tumor size (mean values) } \\
\hline Maximum width at diagnosis $(\mathrm{mm})$ & 41.0 (range, 15-80) \\
\hline Maximum length at diagnosis $(\mathrm{mm})$ & 37.3 (range, 18-75) \\
\hline A-P measure at diagnosis $(\mathrm{mm})$ & 35.2 (range, 13-70) \\
\hline \multicolumn{2}{|l|}{ Nodal status } \\
\hline $\mathrm{N}+$ & $37(26.8)$ \\
\hline $\begin{array}{l}\text { Level } 1 \text { (internal, external iliac, } \\
\text { obturator) }\end{array}$ & $22(15.9)$ \\
\hline $\begin{array}{l}\text { Level } 2 \text { (+ common iliac, aortic } \\
\text { bifurcation) }\end{array}$ & $8(5.8)$ \\
\hline Level 3 (+ para-aortic) & $7(5.1)$ \\
\hline $\mathrm{N}-$ & $101(73.2)$ \\
\hline \multicolumn{2}{|l|}{ Concomitant chemotherapy } \\
\hline Yes & $130(94.2)$ \\
\hline No & $8(5.8)$ \\
\hline
\end{tabular}


chemotherapy (carboplatin-paclitaxel) was applied due to primary advanced tumors. Hemoglobin value was analyzed as a prognostic factor and the mean value at the start of therapy was $127 \mathrm{~g} / 1$ (range, 61-153 g/l).

The median follow-up time for patients alive $(n=101)$ was 44.0 months (range, 3-115 months). In the compete series, the median follow-up time was 37.5 months (range, 3-115 months). Thirty-four patients died because of cervical cancer $(24.6 \%)$, and three patients died due to other diseases $(2.2 \%)$ at the time of last follow-up. The schedule for follow-up was the following: 1 month after the end of radiotherapy, every 3 months during the first year, every 4 months in the second and third year, every 6 months in the fourth to fifth year, and then annually for some patients until ten years.

FIGO stage distribution was stage I 21/138 (15.2\%), stage II 83/138 (60.1\%), stage III 21/138 (15.2\%), and stage IV 13/138 (9.4\%). The mean size of the tumors was $41.0 \mathrm{~mm}$ in maximal width (range, $15-80 \mathrm{~mm}$ ) measured on an MRI image (Table 1). Type of histology was squamous cell carcinoma in 113/138 (81.9\%) cases, adenocarcinomas in 19/138 $(13.8 \%)$ cases, adenosquamous cell carcinomas in 3/138 (2.2\%) cases, and other types of cancers in 3/138 cases.

Nodal stage was assessed by imaging (computed tomography - CT or magnetic resonance imaging - MRI) in all patients. Laparoscopic nodal staging was not used in this series. Pathological lymph nodes were defined as lymph nodes $>1 \mathrm{~cm}$ in size, loss of oval shape on imaging, or positive on positron emission tomographycomputed tomography (PET-CT) imaging. Thirty-seven patients $(26.8 \%)$ presented positive lymph nodes. Positive lymph nodes were classified into three levels, such as lower $(24 / 37 ; 64.9 \%)$ or upper $(3 / 37 ; 8.1 \%)$ pelvic and para-aortic $(10 / 37 ; 27.0 \%)$ sites (Table 1$)$.

The mean age of patients was 53.7 years (range, 23-89 years). A prior history of intercurrent diseases (cardiovascular, diabetes, gastrointestinal, or other types) was recorded in 80 patients $(58.0 \%)$, and prior abdominal surgery in 38 patients (27.5\%). The type of abdominal surgery included gastrointestinal, urological, or gynecological surgery.

The study was approved by the ethics committee (Dnr 2018/482) of Uppsala-Örebro region.

\section{External beam radiotherapy}

The radiotherapy treatment consisted of external beam pelvic radiotherapy (EBRT) and IGABT. A conventional (standard, 3D conformal) 4-field box technique was used in 106 cases $(76.8 \%)$, intensity-modulated radiotherapy (IMRT) in 21 cases (15.2\%), and volumetric-modulated arc therapy (VMAT) in 11 cases $(8.0 \%)$. The mean total external dose was 51.9 Gy (range, 45-68.4 Gy). The mean dose

Table 2. Dose constraints to high-risk clinical target volume (HRCTV) and organs at risk (OARs)

\begin{tabular}{ll}
$\mathrm{D}_{90} \mathrm{HRCTV} \mathrm{EQD2}$ & $>85 \mathrm{~Gy}$ \\
\hline Bladder $\mathrm{D}_{2 \mathrm{~cm}^{3}} \mathrm{EQD2}_{3}$ & $<90 \mathrm{~Gy}$ \\
\hline Rectum $\mathrm{D}_{2 \mathrm{~cm}^{3}} \mathrm{EQD2}_{3}$ & $<75 \mathrm{~Gy}$ \\
\hline Sigmoid $\mathrm{D}_{2 \mathrm{~cm}^{3}} \mathrm{EQD2}_{3}$ & $<75 \mathrm{~Gy}$
\end{tabular}

per fraction was 1.8 Gy (range, 1.8-2.3 Gy). The mean overall treatment time (OTT) was 47.9 days (range, 32-93 days).

\section{Brachytherapy (IGABT)}

The median number of fractions was 4.0 (range, 1-5 fractions). The median dose $\left(\mathrm{EQD}_{2}, \alpha / \beta=10\right)$ per fraction was 8.0 Gy (range, 8.0-9.9 Gy). A ring applicator set was used in all cases. Two different ring diameters were used: $26 \mathrm{~mm}$ in 45 cases $(33.8 \%$ ) and $30 \mathrm{~mm}$ in 88 patients $(66.2 \%)$. The length of intrauterine tube varied between 20 and $60 \mathrm{~mm}$, and the angle between the tube and the shaft of applicator was $60^{\circ}$. The high-risk clinical target volume (HRCTV) was significantly larger in fractions 1-2 (55-57 $\left.\mathrm{cm}^{3}\right)$ as compared with fractions 3-4 (48-49 $\left.\mathrm{cm}^{3}\right)$ (dependent $t$-test; $p=0.0014)$. In $86 / 138$ patients $(62.3 \%)$, interstitial needles were used. The number of needles varied between two and nine, and the median number was six. Needles were added to optimize the dose coverage of the target volume. The intracavitary/interstitial HDR brachytherapy was performed as follows. At the time of implantation, an interstitial ring applicator (Elekta, Stockholm, Sweden) was inserted with the ring positioned in vaginal vault and the tube located intra-uterine. Interstitial needles were added when deemed necessary, in order to cover the target volume with adequate dose. After implantation, the application was fixed by vagina packing. A Foley catheter was placed in the bladder and pulled towards the bladder base and fixed. The Foley catheter in the bladder also acted as a stabilization of the geometry. The patient was then transported to the MRI/CT unit for imaging. In the image study, HRCTV was defined according to European recommendations from the GEC-ESTRO GYN working group [12]. Organs at risk (OARs), such as bladder, rectum, and sigmoid were also defined. In the same image set, the applicators were reconstructed, and an optimized dose distribution based on the dose constraints (Table 2) for the HRCTV and OARs were created using dose planning system OncentraBrachy (Elekta, Stockholm, Sweden). This procedure was repeated for all (four) fractions in two consecutive days, separated by two weeks. One implant was performed per fraction. The first and third fractions were based on an MRI-study, and fractions two and four were based on a CT-study. The CT-study was co-registered with the MRI-study to visualize the MRI-target in the CT-study, as shown by Nesvacil et al. [12]. Before imaging and dose delivery, the bladder was emptied and refilled with a fixed liquid volume of $50 \mathrm{~cm}^{3}$, and a catheter was inserted into rectum to prevent any gas filling.

\section{Toxicity evaluation}

Late toxicity was evaluated at or after 6 months from the completion of radiotherapy using the common toxicity criteria v. 3.0 (CTCAE) [13].

\section{Statistics}

In the statistical analyses, the Pearson $\chi^{2}$ test, the $t$-test (independent and dependent groups), binary logistic regression analysis (univariate and multivariate), Kaplan-Meier method for survival analysis, log-rank 
and Cox F-test (small numbers) for test of differences were used. Cox proportional hazard regression analysis (univariate and multivariate) was applied for analysis of prognostic factors. A $p$-value $<0.05$ was regarded as statistically significant. Statistica 64 (version 13.0.159.0, 2015) software package (Dell Statistica, Dell Inc., USA) and SPSS Statistics version 25.0 (IBM Corp., Armonk, NY, USA) were used in statistical evaluations.

\section{Results}

\section{Overall treatment time}

The mean overall treatment time (EBRT + brachytherapy) of the complete series was 47.9 days (range, $32-93$ days). In 38 patients $(27.5 \%)$, the OTT $>50$ days (Table 3). The OTT was not a significant predictive (local control, pelvic control, tumor recurrences) or prognostic (cancer-specific survival rate) factors in this study.

\section{Concomitant chemotherapy}

In 130 patients $(94.2 \%)$, concomitant chemotherapy was applied and in 74 patients (53.6\%), with five or more cycles administered. Two groups ( $\leq 4$ cycles and $\geq 5$ cycles) were compared regarding cancer-specific survival rate, and there was no significant (log-rank test, $p=0.945$ ) difference between the survival curves. Moreover, no significant association between the number of chemotherapy cycles administered and the total recurrence rates was observed. This was true in the complete series but also in a high-risk subgroup (lymph node-positive cases and/or FIGO stage III-IV). Late toxicity (overall or intestinal) did not increase with the number of chemotherapy cycles given.

\section{Overall tumor control after primary therapy}

In 120/138 (87\%) patients, no evidence of disease (complete remission) at the first follow-up visit ( 3 months) after the end of radiochemotherapy was noted. Four patients presented loco-regional persistent disease and in 14 patients, distant residual diseases were observed.

\section{Local control}

The local control rate at the end of therapy was $97.1 \%$ (134/138 cases). Four patients had a persistent disease. Assessment was performed with clinical evaluation and MRI/PET-CT at the first follow-up visit after 3 months. During the period of follow-up, four $(2.9 \%)$ pure local recurrences occurred, resulting in 130/138 (94.2\%) overall local control cases. During the same period, seven $(5.1 \%)$ regional recurrences were noted, resulting in a crude loco-regional control rate of $89.1 \%$ (123/138 cases). Patients with loco-regional recurrences had synchronous distant recurrences in five of 11 recurrences $(45.5 \%)$. The local control rate at the end of follow-up was $100 \%$ in stage I, $93.8 \%$ in stage II, $76.2 \%$ in stage III, and $66.7 \%$ in stage IV. Squamous cell carcinomas were locally controlled in $94.7 \%$, and adenocarcinomas and adenosquamous carcinomas in $92.0 \%$ (Pearson $\chi^{2}, p=0.602$ ) of patients. Local control rate was identical in grade 1-2 and grade
Table 3. Dosimetric data

Parameter

Mean (SD)

\begin{tabular}{|c|c|}
\hline \multicolumn{2}{|l|}{ Volume data (brachytherapy) } \\
\hline GTVd $\left(\mathrm{cm}^{3}\right)$, at diagnosis & $36.7(36.8)$ \\
\hline $\mathrm{GTV}_{\mathrm{BT}}\left(\mathrm{cm}^{3}\right)$, fraction 1 & $11.2(10.5)$ \\
\hline $\mathrm{GTV}_{\mathrm{BT}}\left(\mathrm{cm}^{3}\right)$, fraction 2 & $9.0(9.5)$ \\
\hline $\mathrm{GTV}_{\mathrm{BT}}\left(\mathrm{cm}^{3}\right)$, fraction 3 & $5.9(6.0)$ \\
\hline $\mathrm{GTV}_{\mathrm{BT}}\left(\mathrm{cm}^{3}\right)$, fraction 4 & $3.5(2.9)$ \\
\hline HRCTV $\left(\mathrm{cm}^{3}\right)$, fraction 1 & $54.5(25.4)$ \\
\hline HRCTV $\left(\mathrm{cm}^{3}\right)$, fraction 2 & $57.7(24.0)$ \\
\hline HRCTV $\left(\mathrm{cm}^{3}\right)$, fraction 3 & $48.8(19.2)$ \\
\hline HRCTV $\left(\mathrm{cm}^{3}\right)$, fraction 4 & $49.0(22.4)$ \\
\hline Bladder volume $\left(\mathrm{cm}^{3}\right)$ & $111.9(36.2)$ \\
\hline Rectal volume $\left(\mathrm{cm}^{3}\right)$ & $35.1(17.3)$ \\
\hline Sigmoidal volume $\left(\mathrm{cm}^{3}\right)$ & $48.9(33.7)$ \\
\hline \multicolumn{2}{|l|}{ Dose data (EBRT) } \\
\hline $\mathrm{EQD}_{2}(\alpha / \beta=10)(\mathrm{Gy})$ & $51.1(4.9)$ \\
\hline $\mathrm{EQD}_{2}(\alpha / \beta=3)(\mathrm{Gy})$ & $50.0(4.9)$ \\
\hline Overall treatment time (days) & $47.9(8.7)$ \\
\hline \multicolumn{2}{|l|}{ Dose data (physical) (brachytherapy) } \\
\hline Point A (fraction 1, Gy) & $7.0(3.4)$ \\
\hline Point B (fraction 1, Gy) & $1.4(0.3)$ \\
\hline Rectovaginal reference point (fraction 1, Gy) & $3.5(0.9)$ \\
\hline HRCTV (total, $D_{90}, \alpha / \beta=10$, Gy) & $88.4(9.4)$ \\
\hline HRCTV $D_{100}$ (fraction 1, Gy) & $4.8(1.1)$ \\
\hline HRCTV $D_{90}$ (fraction 1, Gy) & $7.0(1.0)$ \\
\hline GTV $D_{100}$ (total, $\alpha / \beta=10$, Gy) & $95.0(26.5)$ \\
\hline \multicolumn{2}{|l|}{ Organs at risk } \\
\hline Bladder $2 \mathrm{~cm}^{3}$ (fraction $\left.1, G y\right)(\alpha / \beta=3)$ & $7.1(2.4)$ \\
\hline Bladder $2 \mathrm{~cm}^{3}$ (total, $\alpha / \beta=3$, Gy) & $73.9(7.4)$ \\
\hline Rectum $2 \mathrm{~cm}^{3}$ (fraction 1 , Gy) $(\alpha / \beta=3)$ & $4.2(1.9)$ \\
\hline Rectum $2 \mathrm{~cm}^{3}$ (total, $\alpha / \beta=3$, Gy) & $65.5(7.2)$ \\
\hline Sigmoid colon $2 \mathrm{~cm}^{3}$ (fraction $\left.1, \mathrm{~Gy}\right)(\alpha / \beta=3)$ & $4.8(2.5)$ \\
\hline Sigmoid colon $2 \mathrm{~cm}^{3}$ (total, $\alpha / \beta=3$, Gy) & $67.4(7.7)$ \\
\hline \multicolumn{2}{|l|}{ Brachytherapy } \\
\hline With needles & $86(62.3 \%)$ \\
\hline Without needles & $52(37.7 \%)$ \\
\hline Number of needles (median, (SD), range) & $6.0(2.2)$ \\
\hline HRCTV D 90 , without needles (Gy) & 81.5 \\
\hline HRCTV $D_{90}$, with needles (Gy) & 88.0 \\
\hline
\end{tabular}


Table 4. Disease outcome and morbidity in the complete series

\begin{tabular}{|c|c|}
\hline Parameter & No. of patients, $n$ (\%) \\
\hline \multicolumn{2}{|l|}{ Local control after treatment } \\
\hline Overall & 134/138 (97.1) \\
\hline$\leq 30 \mathrm{~cm}^{3} \mathrm{CTV}_{\mathrm{HR}}$ & $22 / 22(100)$ \\
\hline$>30 \mathrm{~cm}^{3} \mathrm{CTV}_{\mathrm{HR}}$ & $105 / 109(96.3)$ \\
\hline Stage IB-IIA & $38 / 38(100)$ \\
\hline Stage IIB & $64 / 65(98.5)$ \\
\hline Stage III & 19/21 (90.5) \\
\hline Stage IVA & 9/9 (100) \\
\hline \multicolumn{2}{|c|}{ Nodal control (including para-aortic) } \\
\hline Overall & NA \\
\hline NO and stage I + II & NA \\
\hline N1 and stage III + IVA & NA \\
\hline \multicolumn{2}{|l|}{ Local control (at last follow-up) } \\
\hline Overall & $130 / 138(94.2)$ \\
\hline \multicolumn{2}{|c|}{ Pelvic nodal control (at last follow-up) } \\
\hline Overall & $131 / 138(94.9)$ \\
\hline \multicolumn{2}{|l|}{$\begin{array}{l}\text { Pelvic control (local + nodal) } \\
\text { (at last follow-up) }\end{array}$} \\
\hline Overall & 123/138 (89.1) \\
\hline \multicolumn{2}{|l|}{$\begin{array}{l}\text { Systemic control (excluding } \\
\text { para-aortic failures) }\end{array}$} \\
\hline Overall & 123/138 (89.1) \\
\hline NO and stage I + II & $80 / 83(96.4)$ \\
\hline N1 and stage III + IVA & $38 / 54(70.4)$ \\
\hline \multicolumn{2}{|l|}{ Cancer-specific survival (5-year) } \\
\hline Overall & $68.6 \%$ (95\% Cl: 59.4-77.8\%) \\
\hline NO and stage I+ II & $75.3 \%$ (95\% Cl: 63.1-87.5\%) \\
\hline $\mathrm{N} 1$ and stage III + IVA & $51.6 \%$ (95\% Cl: $37.1-66.1 \%)$ \\
\hline \multicolumn{2}{|l|}{ Overall survival (5-year) } \\
\hline Overall & $65.2 \%$ (95\% Cl: 55.6-74.8\%) \\
\hline NO and stage I + II & 81.3\% (95\% Cl: 70.5-92.1\%) \\
\hline N1 and stage III + IVA & $51.6 \%$ (95\% Cl: 37.1-66.1\%) \\
\hline \multicolumn{2}{|l|}{ Morbidity } \\
\hline Bladder CTCAE $\geq$ G2 & 10/138 (7.3) \\
\hline Bladder CTCAE $\geq$ G3 & $3 / 138(2.2)$ \\
\hline Rectal-sigmoid CTCAE $\geq$ G2 & 19/138 (13.8) \\
\hline Rectal-sigmoid CTCAE $\geq$ G3 & $1 / 138(0.7)$ \\
\hline Vaginal CTCAE $\geq$ G2 & $30 / 138(21.7)$ \\
\hline Vaginal CTCAE $\geq$ G3 & $0 / 138(0.0)$ \\
\hline Bone CTCAE $\geq$ G1 & $12 / 138(8.7)$ \\
\hline Bone CTCAE $\geq$ G2 & $3 / 138(2.2)$ \\
\hline
\end{tabular}

3 tumors. FIGO stage and lymph node status were significantly associated with overall local control rate $(p=0.005, p=0.007)$. The total brachytherapy dose to HRCTV $\left(D_{90}, \alpha / \beta=10\right)$ had no significant impact on local tumor control after primary therapy. However, local control rate versus HRCTV volume and total HRCTV $D_{90}$ dose $(\alpha / \beta=10)$ was most favorable $(94.4 \%)$ in small HRCTV $\leq 30 \mathrm{~cm}^{3}$ and in total HRCTV $D_{90}$ dose $\geq 95$ Gy (Figure 1).

The addition of interstitial needles had no significant effect ( $p=0.291$ ) on local control rate after the end of radiotherapy or on the crude local control rate at the end of follow-up ( $p=0.922)$. The addition of needles was significantly ( $t$-test, $p=0.025$ ) associated with the mean HRCTV volume, which increased from $48.1 \mathrm{~cm}^{3}$ to $58.5 \mathrm{~cm}^{3}$. The HRCTV $\mathrm{D}_{90}$ dose from all brachytherapy treatments increased in mean from 31.4 Gy to 40.3 Gy ( $t$-test, $p<0.0001)$, and the mean total dose to HRCTV volume from $82.5 \mathrm{~Gy}$ to $91.2 \mathrm{~Gy}$ ( $t$-test, $p<0.0001)$. The mean bladder $2.0 \mathrm{~cm}^{3}$ dose $(\alpha / \beta=3)$ increased from $6.3 \mathrm{~Gy}$ to $7.5 \mathrm{~Gy}$ ( $t$-test, $p=0.006$ ), the rectal $2.0 \mathrm{~cm}^{3}$ dose from $3.7 \mathrm{~Gy}$ to $4.3 \mathrm{~Gy}$ ( $t$-test, $p=0.070$ ), and the sigmoid $2.0 \mathrm{~cm}^{3}$ from 3.7 Gy to $5.4 \mathrm{~Gy}(t$-test, $p<0.0001)$.

\section{Pelvic control}

The crude pelvic control at the end of follow-up was in $123 / 138(89.1 \%)$ patients. In four cases, residual tumor after primary therapy was observed, and in 11 cases, local $(n=4)$ or regional $(n=7)$ recurrences within the pelvic area were reported.

\section{Systemic control}

After completed primary therapy, 14 cases had distant residual disease and four cases presented local or loco-regional disease. Therefore, the primary systemic (distant) tumor control occurred in 124/138 (89.9\%) patients. During the time of follow-up, further 30 distant

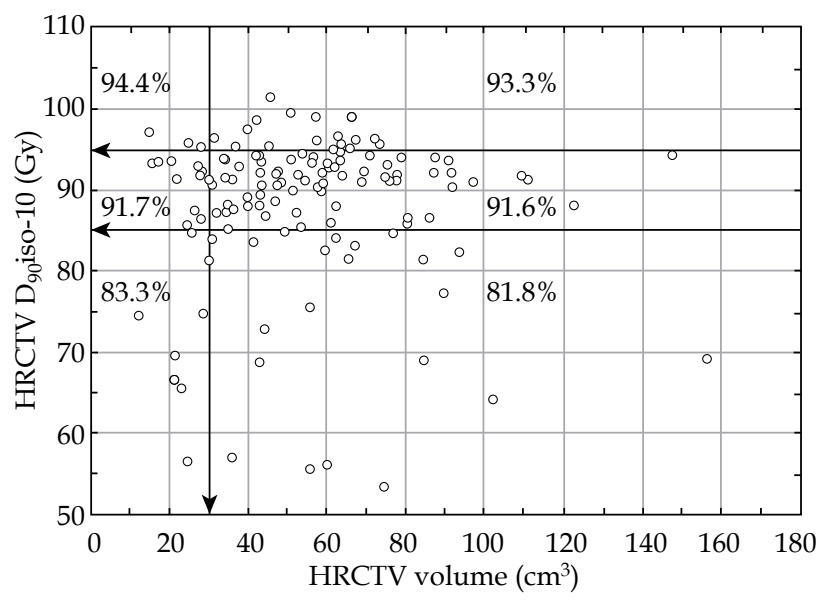

Fig. 1. Local control rate vs. high-risk clinical target volume (HRCTV) and the HRCTV $D_{90}$ dose $(\alpha / \beta=10)$. The most favorable situation is a small HRCTV $\leq 30 \mathrm{~cm}^{3}$ and a total HRCTV $D_{90}$ dose $\geq 95$ Gy. Most tumors are in the interval of HRCTV volume $30-80 \mathrm{~cm}^{3}$ and HRCTV $\mathrm{D}_{90}$ dose $85-95 \mathrm{~Gy}$ 
recurrences $(21.7 \%)$ were recorded, resulting in $94 / 138$ $(68.1 \%)$ of distant tumor control (Table 4$)$. Distant metastases were significantly (Pearson $\chi^{2}, p=0.007$ ) associated with tumor stage: $14.3 \%$ in stage I, $15.7 \%$ in stage II, $33.3 \%$ in stage III and $53.9 \%$ in stage IV. Among squamous cell carcinomas, $19.5 \%$ of distant recurrences were recorded, and among adenocarcinomas and adenosquamous carcinomas $32.0 \%$ of distant recurrences were observed (Pearson $\left.\chi^{2}, p=0.169\right)$. Tumor grade was not significantly associated with distant recurrences. Patients with positive lymph nodes at diagnosis had a $35.1 \%$ of risk of distant recurrences as compared to $16.8 \%$ of patients with negative lymph nodes (Pearson $\chi^{2}, p=0.021$ ). Patients treated with less than three brachytherapy fractions presented a significantly (Pearson $\chi^{2}, p=0.012$ ) increased risk of distant metastases. The optimum number of fractions appeared to be at least four fractions.

Table 5. Prognostic factors for cancer-specific survival rate. Cox proportional regression analyses (univariate and multivariate analyses)

\begin{tabular}{|c|c|}
\hline Prognostic factors & Hazard ratio $(95 \% \mathrm{Cl})$ \\
\hline \multicolumn{2}{|l|}{ Factor univariate analyses } \\
\hline FIGO stage (I-II vs. III-IV) & $\begin{array}{c}0.279(0.141-0.553) \\
p<0.001\end{array}$ \\
\hline $\begin{array}{l}\text { Lymph node metastases } \\
\text { (pelvic or para-aortic) }\end{array}$ & $\begin{array}{c}2.952(1.488-5.856) \\
p<0.002\end{array}$ \\
\hline Primary cure (complete remission) & $\begin{array}{c}0.146(0.071-0.300) \\
p<0.0001\end{array}$ \\
\hline Primary local control & $\begin{array}{c}0.132(0.044-0.397) \\
p<0.001\end{array}$ \\
\hline Overall local control & $\begin{array}{c}0.198(0.080-0.490) \\
p<0.001\end{array}$ \\
\hline Pelvic control & $\begin{array}{c}0.082(0.038-0.176) \\
p<0.0001\end{array}$ \\
\hline Distant control & $\begin{array}{c}0.063(0.029-0.138) \\
p<0.0001\end{array}$ \\
\hline $\begin{array}{l}\text { Hemoglobin level at start } \\
\text { of treatment }\end{array}$ & $\begin{array}{c}0.962(0.947-0.978) \\
p<0.0001\end{array}$ \\
\hline $\begin{array}{l}\text { Total extern dose (Gy), } \\
\text { negative impact }\end{array}$ & $\begin{array}{c}1.118(1.051-1.189) \\
p<0.001\end{array}$ \\
\hline $\begin{array}{l}\text { Total HRCTV } D_{90}(\alpha / \beta=10) G y \text {, } \\
\text { positive impact }\end{array}$ & $\begin{array}{c}0.963(0.938-0.989) \\
p<0.010\end{array}$ \\
\hline \multicolumn{2}{|l|}{ Factor multivariate analysis } \\
\hline $\begin{array}{l}\text { Hemoglobin level at start } \\
\text { of treatment }\end{array}$ & $\begin{array}{c}0.974(0.957-0.991) \\
p<0.003\end{array}$ \\
\hline Primary cure (complete remission) & $\begin{array}{c}0.220(0.078-0.624) \\
p<0.004\end{array}$ \\
\hline Distant control & $\begin{array}{c}0.387(0.165-0.905) \\
p<0.030\end{array}$ \\
\hline All other factors & $\begin{array}{c}\text { Non-significant } \\
\text { in multivariate } \\
\text { analysis }\end{array}$ \\
\hline Total HRCTV $D_{90}(\alpha / \beta=10)$ Gy & $\begin{array}{l}\text { Significant if distant } \\
\text { control excluded }\end{array}$ \\
\hline
\end{tabular}

\section{Recurrences}

The overall rate of recurrences of the complete series occurred in 35/138 (25.4\%) of patients. Local recurrence in $4 / 138(2.9 \%)$, regional recurrences in $7 / 138(5.1 \%)$, and distant recurrences in 30/138 (21.7\%) cases. In six patients, multiple sites of recurrences were recorded. The mean time from diagnosis to recurrence was 14.7 months (range, 3-40 months). FIGO stage, hemoglobin value at start of therapy, and the total dose to high-risk clinical target volume were significant and independent predictive factors. Lymph node status (metastases) at diagnosis were just above the significance level $(p=0.067)$ in multivariate logistic regression analysis (Table 5). The use of needles during brachytherapy was not significantly associated with overall, local, loco-regional, or distant recurrence rate. The total brachytherapy dose to HRCTV was significantly (logistic regression analysis, $p=0.003$ ) associated with the overall recurrence rate. Distant recurrences were also highly significantly (logistic regression analysis, $p=0.0008$ ) associated with HRCTV brachytherapy dose. Total external dose was non-significant after correction for the brachytherapy dose. The size of HRCTV at brachytherapy was not associated with tumor recurrences.

\section{Survival}

There were 37 deaths ( 34 cases due to cancer and 3 cases due to other diseases) during the study period, giving a 5-year overall survival of $65.2 \%$ (95\% CI: $55.7-74.7 \%)$ and cancer-specific survival of $68.6 \%$ (95\% CI: 59.4-77.8\%) (Figure 2). FIGO stage had a significant impact on both overall and cancer-specific survival rate (Figure 3). Tumor size was not significantly $\left(\chi^{2}\right.$ test, $\left.p=0.849\right)$ associated with survival rate in this study. Adenocarcinomas and adenosquamous carcinomas had a slightly worse prognosis than squamous cell carcinomas. However, the difference was not statistically significant (log-rank test, $p=0.109$ ) in this series of patients.

The 5-year cancer-specific survival rate was $77.0 \%$ for node-negative patients, and $50.7 \%$ for node-positive patients (log-rank test, $p=0.0013$ ). The level of enlarged nodes was of prognostic importance for level 2-3 as compared to level 1 . Only eight patients did not receive

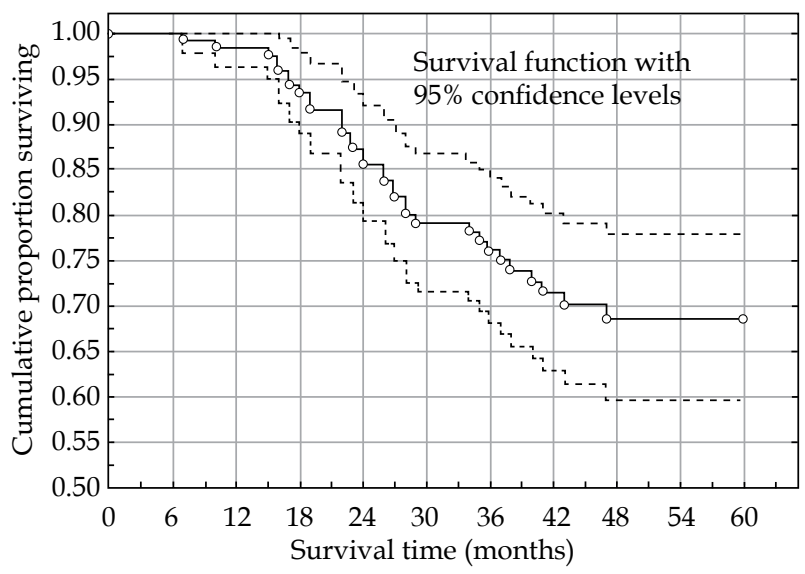

Fig. 2. Cancer-specific survival rate of the complete series $(n=138)$. Survival probability with $95 \%$ confidence levels 


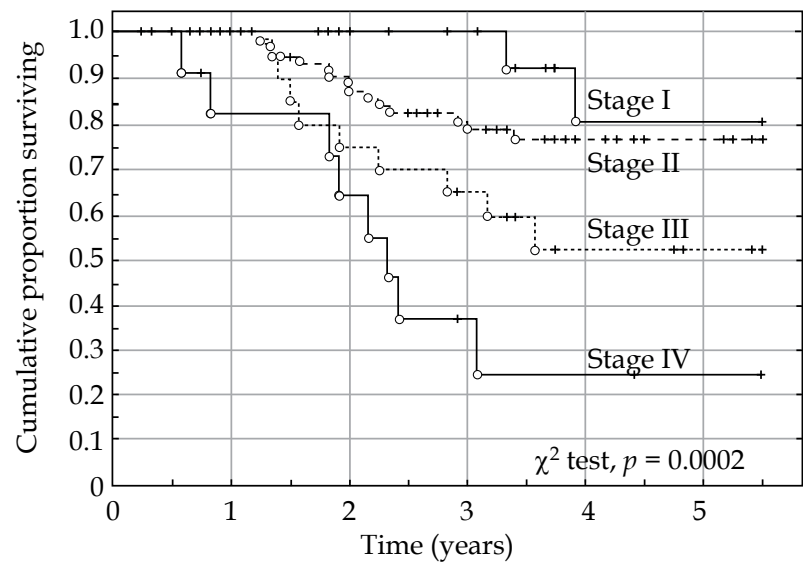

Fig. 3. Cancer-specific survival rate versus FIGO stage (stage I-IV). There was a highly significant $\left(\chi^{2}\right.$ test, $\left.p=0.0002\right)$ difference between the four stages

concomitant chemotherapy, and therefore, the impact of chemotherapy was difficult to evaluate in this series. The presence of needles or not during brachytherapy was not significantly associated with cancer-specific survival rate (log-rank test, $p=0.623$ ) in the complete series, but patients with tumors in FIGO stage III-IV had a significantly (Cox F-test, $p=0.026$ ) better cancer-specific survival rate if treated with needles. It appeared that patients with adenocarcinoma (cancer-specific survival rate) benefited from treatment with needles (Cox F-test, $p=0.058$ ). Adenocarcinomas had a significantly larger GTVd than squamous cell carcinomas $\left(44.8 \mathrm{~cm}^{3}\right.$ vs. $\left.31.2 \mathrm{~cm}^{3}\right)$ at diagnosis ( $t$-test, $p=0.038)$. The $\mathrm{D}_{90}$ dose to HRCTV was significantly associated with cancer-specific survival rate, but not the volume of HRCTV. The number of brachytherapy fractions resulted to be of prognostic importance, and 4-5 fractions appeared to be the optimum number (Figure 4).

Table 6. Prognostic factors for cancer-specific survival rate. Cox proportional regression analyses (univariate and multivariate analyses). Analysis of external and brachytherapy doses after correction for FIGO stage

\begin{tabular}{lc} 
Prognostic factors & Hazard ratio $(95 \% \mathrm{Cl})$ \\
\hline Factor univariate analyses & \\
\hline FIGO stage (III-IV vs. I-II) & $3.635(1.834-7.206)$, \\
& $p<0.001$ \\
\hline Total extern dose $(\mathrm{Gy})$ & $1.118(1.051-1.189)$, \\
& $p<0.001$ \\
\hline Total HRCTV $D_{90}(\alpha / \beta=10)$ & $0.963(0.938-0.988)$, \\
fractions 1-5 & $p<0.01$ \\
\hline Factor multivariate analysis & \\
\hline FIGO stage (III-IV vs. I-II) & $3.541(1.418-8.844)$, \\
& $p<0.007$ \\
\hline Total extern dose $(\mathrm{Gy})$ & $1.013(0.934-1.098)$, \\
& $p=0.763$ \\
\hline Total HRCTV $D_{90}(\alpha / \beta=10)$ Gy & $0.967(0.937-0.997)$, \\
fractions 1-5 & $p<0.040$
\end{tabular}

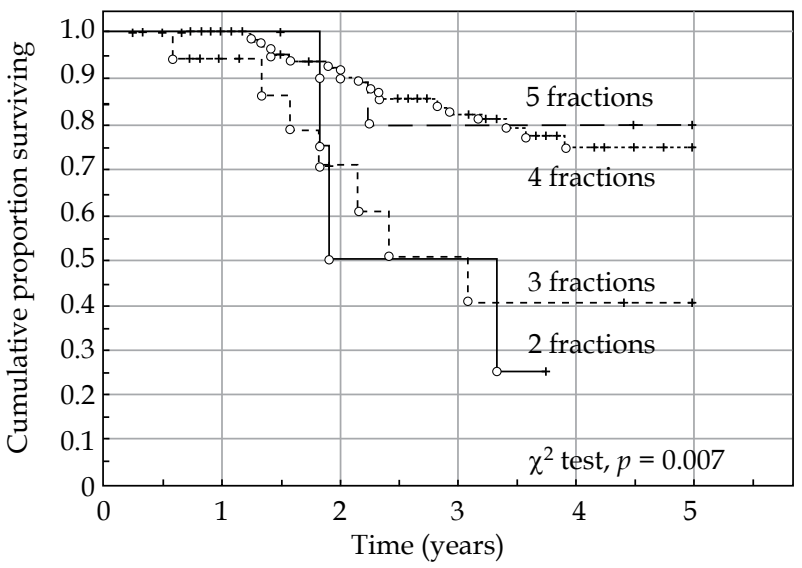

Fig. 4. Cancer-specific survival rate versus number of brachytherapy fractions. There was a significant difference $\left(\chi^{2}\right.$ test, $p=0.007$ ) between 2-3 fractions and 4-5 fractions

\section{Prognostic factors}

Ten significant prognostic factors for cancer-specific survival rate were identified in univariate Cox proportional regression analyses. However, of these factors, only three, such as primary cure rate (complete remission after therapy), distant tumor control (no distant recurrences), and hemoglobin value at the start of therapy were significant and independent in a Cox multivariate regression analysis (Table 4). In a multivariate analysis restricted only to factors available at the end of primary therapy, there were three significant and independent prognostic factors for cancer-specific survival rate, including total dose $\left(D_{90}, \alpha / \beta=10\right)$ to HRCTV delivered by brachytherapy $(\mathrm{HR}=0.96, p=0.014)$, primary cure rate $(\mathrm{HR}=0.25$, $p=0.010)$, and hemoglobin value at the start of therapy $(\mathrm{HR}=0.98, p=0.043)$. Gross tumor volume (GTV) at diagnosis $(\mathrm{GTVd})$, GTV at brachytherapy $\left(\mathrm{GTV}_{\mathrm{BT}}\right)$, and the difference between them (tumor shrinkage) were non-significant prognostic factors (Table 6).

\section{Late bladder and intestinal toxicity}

Bladder toxicity (CTCAE $\geq$ G2) was recorded in 10 of 138 patients $(7.3 \%)$. In 3 cases $(2.2 \%)$ only, CTCAE G3 toxicity was seen. Bladder toxicity was highly significantly $(t$-test, $p=0.002)$ associated with the dose $\left(\mathrm{EQD}_{2}, \alpha / \beta=3\right)$ to $2.0 \mathrm{~cm}^{3}$ of the bladder. However, the total external dose $\left(\mathrm{EQD}_{2}, \alpha / \beta=3\right)$ was not significantly $(p=0.140)$ associated with toxicity of the bladder. Age was not a risk factor for late bladder toxicity $(p=0.613)$. A history of prior diseases was not associated with late bladder toxicity.

Bowel CTCAE $\geq$ G2 toxicity was noted in 19/138 (13.8\%) patients, and bowel CTCAE $\geq$ G3 in 1/138 (0.7\%) case. Bowel toxicity CTCAE $\geq$ G1 was significantly (Pearson $\chi^{2}, p=0.005$ ) associated with a prior history of abdominal surgery (gastrointestinal, urological, or gynecological). In the group with no prior surgery, $41 \%$ of toxicity was noted, and in the group with surgery, $71 \%$ of bowel toxicity was recorded. CTCAE $\geq \mathrm{G} 2$ toxicity increased from $11 \%$ to $21 \%$ after prior abdominal surgery. Prior diseases (cardiovascular, diabetes, gastrointestinal, 
and gynecological) also increased the risk of late bowel toxicity CTCAE $\geq \mathrm{G} 2(p=0.046)$. The EQD 2 dose per fraction was significantly ( $t$-test, $p=0.037$ ) associated with late intestinal reactions of any grade.

\section{Vaginal toxicity}

Vaginal toxicity was significantly (Pearson $\chi^{2}, p=0.022$ ) associated (increased) with the number of brachytherapy fractions administered. The size of HRCTV was also associated with the rate of vaginal toxicity (Pearson $\chi^{2}, p=$ $0.047)$. The total external dose $\left(\mathrm{EQD}_{2}, \alpha / \beta=3\right)$ was only weakly (binary logistic regression analysis, $p=0.072$ ) associated with the risk of vaginal toxicity. The mean dose to the recto-vaginal reference point was 65.7 Gy (range, 58-73 Gy). However, this dose was not significantly (logistic regression analysis, $p=0.468$ ) associated with late vaginal toxicity in this series of patients. However, data of doses in this reference point was only available in 56 cases.

Vaginal toxicity (all grades) was more common $(61 / 87$ patients, $70.1 \%)$ in the group treated with needles as compared with the group without needles (30/52 cases, $57.7 \%)$. However, the difference was not statistically significant (Pearson $\chi^{2}$ test, $p=0.136$ ). Grade 2 toxicity was also more frequent in the needle group (21/86 cases, $24.4 \%)$ than in the non-needle group ( $9 / 52$ patients, $17.3 \%)$, but still not significant $(p=0.326)$.

\section{Bone toxicity}

Bone CTCAE $\geq$ G1 toxicity occurred in 12/138 (8.7\%) patients, and bone CTCAE $\geq$ G2 toxicity in 3/138 (2.2\%) cases. Bone toxicity was neither associated with total external pelvic dose nor with total external and intracavitary dose to high-risk clinical target volume. In this study, other predictive factors were not identified (Table 7). However, a substantial number of cases had missing data on bone toxicity.

\section{Discussion}

In this study, the importance of modern 3D image-guided brachytherapy was emphasized. The number of brachytherapy fractions and total brachytherapy dose $\left(D_{90}, \alpha / \beta=10\right)$ was significantly associated with overall recurrence rate, distant recurrences, and cancer-specific survival rate. The importance of brachytherapy dose to the high-risk clinical target volume (HRCTV) was shown, in a multivariate analysis, to be both significant and independent with the primary cure rate (complete remission) and hemoglobin value at the start of therapy. A total brachytherapy dose greater than $45 \mathrm{~Gy}\left(\mathrm{EQD}_{2}\right)$ had a significantly positive impact on cancer-specific survival rate. However, the total external dose (after correction for brachytherapy dose) was not significantly associated with treatment outcome and negatively correlated with a brachytherapy dose. Thus, an increased external pelvic dose (or boost dose) would probably not compensate for exclusion of brachytherapy treatment. Prior studies have also confirmed the advantage of combined external and intracavitary therapy compared with external therapy alone $[9,14]$. On the other hand, the size of HRCTV and the use of interstitial needles were neither statistically associated with tumor recurrences nor with cancer-specific survival rate in the complete series. The use of needles was significantly associated with the size of HRCTV and therefore, the potential risk of late radiation reactions. The total dose $\left(D_{90}\right)$ to the HRCTV (external plus intracavitary) was significantly higher in the group treated with needles. This agrees with the study by Fokdal et al. [10]. In contrast, the local control rate was higher, but not significantly different in the group treated with $(95.4 \%)$ or without $(92.3 \%)$ needles. This was true in the complete series and in patients with HRCTV $>30 \mathrm{~cm}^{3}$. An interesting result in our series was a survival benefit of adenocarcinomas as well as tumors in FIGO stage III-IV when needles were used. Thus, our results did not statistically support the theory in Fokdal's study of improved therapeutic ratio in the complete group treated, but probably for adenocarcinomas and advanced tumors in FIGO stage III-IV, with combined intracavitary and interstitial therapy. The gross tumor volume at diagnosis was larger for adenocarcinomas than for squamous cell carcinomas, which may be a reason for this therapeutic benefit.

Table 7. Predictive factors for tumor recurrences. Logistic regression analyses (univariate and multivariate analyses)

\begin{tabular}{|c|c|}
\hline Predictive factors & $\begin{array}{c}\text { Hazard ratio }(95 \% \mathrm{Cl}) \\
p \text {-value }\end{array}$ \\
\hline \multicolumn{2}{|l|}{ Factor univariate analyses } \\
\hline FIGO stage (III-IV vs. I-II) & $\begin{array}{c}3.977(1.722-9.185) \\
p<0.001\end{array}$ \\
\hline $\begin{array}{l}\text { Lymph node metastases } \\
\text { (pelvic or para-aortic) }\end{array}$ & $\begin{array}{c}2.761(1.218-6.261) \\
p<0.02\end{array}$ \\
\hline $\begin{array}{l}\text { Histology (adeno- vs. squamous } \\
\text { cell carcinoma) }\end{array}$ & $\begin{array}{c}2.347(0.940-5.860) \\
p<0.07\end{array}$ \\
\hline $\begin{array}{l}\text { Hemoglobin value at start } \\
\text { of therapy }\end{array}$ & $\begin{array}{c}0.956(0.932-0.981) \\
p<0.001\end{array}$ \\
\hline Number of brachytherapy fractions & $\begin{array}{c}0.530(0.286-0.980) \\
p<0.05\end{array}$ \\
\hline Total HRCTV $D_{90}(\alpha / \beta=10)$ dose (Gy) & $\begin{array}{c}0.957(0.921-0.995) \\
p<0.03\end{array}$ \\
\hline Other factors & $\begin{array}{c}\text { Non-significant in } \\
\text { univariate } \\
\text { analyses }\end{array}$ \\
\hline \multicolumn{2}{|l|}{ Factor multivariate analysis } \\
\hline FIGO stage (III-IV vs. I-II) & $\begin{array}{c}3.125(1.057-9.245) \\
p<0.04\end{array}$ \\
\hline $\begin{array}{l}\text { Lymph node metastases } \\
\text { (pelvic or para-aortic) }\end{array}$ & $\begin{array}{c}2.658(0.933-7.573) \\
p<0.07\end{array}$ \\
\hline $\begin{array}{l}\text { Hemoglobin value at start of } \\
\text { therapy }\end{array}$ & $\begin{array}{c}0.963(0.936-0.991) \\
p<0.01\end{array}$ \\
\hline Total HRCTV $D_{90}(\alpha / \beta=10)$ dose (Gy) & $\begin{array}{c}0.932(0.891-0.975) \\
p<0.003\end{array}$ \\
\hline Other factors & $\begin{array}{l}\text { Non-significant } \\
\text { in multivariate } \\
\text { analysis }\end{array}$ \\
\hline
\end{tabular}


The study by Fokdal et al. included 574 patients [10] as compared to 138 patients in our study, which could be of importance for the statistical outcome.

The most important predictive factor for tumor recurrences was the dose to the HRCTV (total and from brachytherapy), but not the size of HRCTV or the use of needles. Increasing the external dose and then decreasing the dose of brachytherapy had a negative prognostic impact on tumor recurrences and on cancer-specific survival rate. The time interval between diagnosis and the first brachytherapy fraction had a highly significant impact on the cancer-specific survival rate.

The crude local control rate in this series was $94.2 \%$, which was superior of that reported in the RetroEMBRACE study $(90.6 \%)$ presented by Sturdza et al. [8]. However, the crude pelvic control rate was the same $(87.0 \%)$ in both studies. In two older studies $[15,16]$ from US using conventional brachytherapy with or without chemotherapy, pelvic control rate was $77 \%$.

The overall recurrence rate in this series was $25.4 \%$, which is an improvement as compared to our earlier study with $30 \%$ of recurrences [17]. However, this difference was not statistically significant. In the RetroEMBRACE-study, the overall recurrence rate was 30.4\% [8], similarly to our older data.

The 5-year cancer-specific survival in our series was $69 \%$ as compared to $73 \%$ in the Retro-EMBRACE series. This difference could be explained by a difference in FIGO stage distribution. In our series, $10 \%$ of the tumors were in stage IV, but only 3\% in the Retro-EMBRACE series [8]. After correction for this difference in stage distribution, the 5 -year cancer-specific survival was $73 \%$ also in our study. In a prior study with standard brachytherapy from our institution published in 2010, the cancer-specific survival rate was $65 \%$ [17]. Thus, in our institution, we have improved the 5-year cancer-specific survival rate by

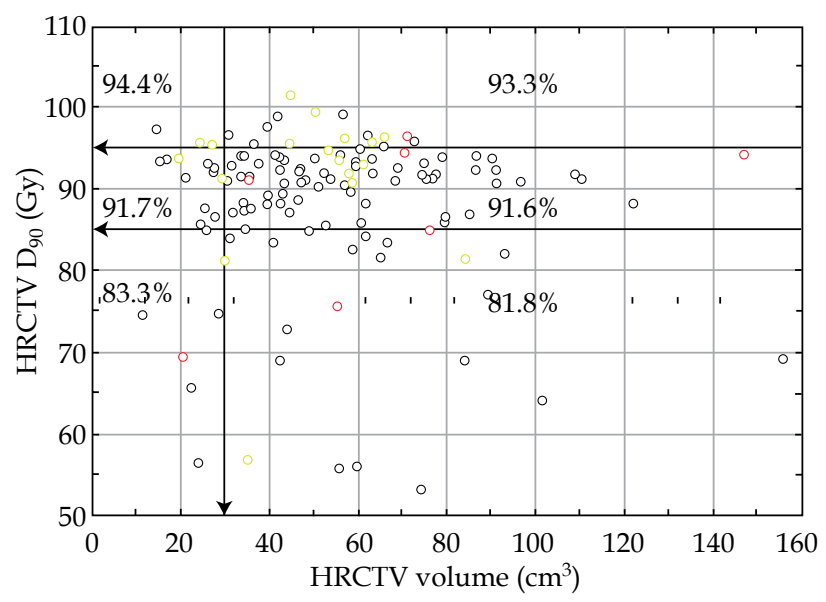

Fig. 5. Tumors with no local control (red circles) and patients with late intestinal toxicity CTCAE $\geq$ G2 (yellow circles) are plotted in a scatter diagram of high-risk clinical target volume (HRCTV) vs. HRCTV $\mathrm{D}_{90}$ dose. The tumors with no local control are widely spread, with no distinct pattern in the diagram. Besides a few "outliers", the cases with late toxicity are well-concentrated in the upper left corner with smaller volumes $\left(<70 \mathrm{~cm}^{3}\right)$ and higher doses in general $\mathrm{D}_{90}>90 \mathrm{~Gy}$
8\%. A study from the Netherlands by Rijkmans et al. [18] showed a highly significantly improved 3-year overall survival in the group with image-guided brachytherapy (86\%) as compared to conventional brachytherapy (51\%). The 3-year overall survival in our series was $75 \%$ for comparison.

In our study, the OTT was not a significant predictive or prognostic factor. However, in the Retro-EMBRACE study on 488 patients presented by Tanderup et al. [19], the OTT was significantly associated with local tumor control in both univariate and multivariate analyses. The recommendation was to keep the OTT shorter than 50 days.

In our study, 74 patients $(54 \%)$ received $\geq 5$ cycles of chemotherapy. In the EMBRACE I study, the corresponding figure was $70 \%$ [20]. The number of chemotherapy cycles was neither a predictive, nor a prognostic factor for therapy outcome in our study. In a study by Schmid et al. [21], the number of chemotherapy cycles was found to be of prognostic importance in a high-risk group (positive lymph nodes and stage III-IV) for distant recurrences. We could not confirm this finding in our study. In a large meta-analysis by Vale et al. (more than 3,000 patients), it was suggested that concomitant chemotherapy improved loco-regional disease-free interval by $6 \%$ at 5 years. However, the pelvic recurrence rate was $23 \%$ identical to other series without concomitant chemotherapy [15]. In our present study the pelvic recurrence rate was only $9 \%$.

Serious bladder toxicity was recorded in $2 \%$ of patients and it was highly significantly associated with the $2.0 \mathrm{~cm}^{3}$ dose to the bladder.

Bowel toxicity (all grades) was significantly associated with a prior history of abdominal surgery, which was reported in our previous publication [11]. Additionally, prior diseases (cardiovascular disease and diabetes) increased the risk of late bowel toxicity. The dose of brachytherapy fractions also increased the risk of late intestinal reactions. However, the $2.0 \mathrm{~cm}^{3}$ total dose to the rectum was not significantly associated with bowel toxicity in our study. On the other hand, very few serious late reactions (grade 3-4) were noted in our study. In a study by Mazeron et al. [22] including 960 patients (EMBRACE I), a dose-volume effect was noted for $\mathrm{D}_{2 \mathrm{~cm}^{3}}$ $\leq 65 \mathrm{~Gy}$ and $\mathrm{D}_{2 \mathrm{~cm}^{3}} \geq 75 \mathrm{~Gy}$, with minor or major late rectal toxicity, respectively. In a prior study published from our institution, serious late intestinal reactions (grade 3-4) occurred in 14\% of patients after a combined treatment of external beam pelvic radiotherapy and conventional brachytherapy [9]. In the present study, grade 3 toxicity was recorded in only $3 \%$. No grade 4 toxicity was recorded in this series. This was an important improvement in the present study using MRI-guided IGABT as compared with our older data not using this technique [11].

Vaginal toxicity was associated with the number of brachytherapy fractions, and the size of the HRCTV was associated with vaginal toxicity. Vaginal toxicity (all grades) was more common in the group of patients treated with needles.

Bone toxicity (all grades) occurred in $9 \%$ of patients. Bone toxicity was not associated with total external or intracavitary dose to the high-risk clinical target volume. 
However, in this study, a substantial number of patients had missing data regarding this type of toxicity.

All types of late intestinal toxicity occurred in a low rate, especially serious grade 3-4 reactions. The individually designed external pelvic irradiation and adaptive brachytherapy (with or without needles) is probably one important explanation. The dose to organs at risk was carefully evaluated and limited based on the well-known tolerability of these organs. The image-guided brachytherapy technique, using MRI before and during treatment, is of importance to achieve these results. This is a significant improvement as compared with older data on conventional brachytherapy both from our institution [11] and from other centers [19].

Analyses of late toxicity of the intestine and the bladder by 3D scatter plot (Figure 5) confirmed the importance of the total dose to the HRCTV (>90 Gy, $\alpha / \beta=3$ ), not the HRCTV volume. All intestinal toxicity (CTCAE $\geq$ G2), except three cases, and all bladder toxicity (CTCAE $\geq$ G2), except two cases, occurred in patients who had received a $\mathrm{D}_{90}$ dose $>90$ Gy to the HRCTV volume. Five patients reported both late bladder and intestinal toxicity, and all of them received a $D_{90}$ dose $>90$ Gy to the HRCTV. However, analysis of all late toxicity (CTCAE $\geq$ G1) showed another pattern, where both the dose level and the volume of HRCTV were of importance.

Recently, the problem with distal parametrial and pelvic wall invasion was addressed in a two institutional study by Mahantshetty et al. [23], using a newly developed applicator, which allowed the use of both parallel and oblique needles (Vienna-II). Treatment outcomes were comparable with our results (local control, recurrences, and survival data) when analyzed in FIGO stages IIB-IVB, but with a substantial higher rate of serious late side effects (20\% of grade 3-4 toxicity, including 4 fistulas) and acute treatment-related complications (active bleeding in $27 \%$ of cases). In a smaller series of 10 patients, with a total of 40 fractions, another new hybrid applicator (Venezia) was tested and was found to be feasible, enabling improved dose coverage and sparing organs at risk [24].

\section{Conclusions}

Data from our study showed a local control rate $>94 \%$ for a $D_{90}$ dose $>95$ Gy to the HRCTV. Our results indicate a survival benefit for adenocarcinomas and FIGO stage IIIIV carcinomas with use of interstitial needles. To reduce late bladder and intestinal toxicity, the recommended $\mathrm{D}_{90}$ dose should be $<90$ Gy to the HRCTV. These results agree with data presented in the Retro-EMBRACE study [19]. The reported data are excellent for local and loco-regional tumor control as well as for late toxicity of organs at risk. However, still, there is a problem with a rather high-rate of distant recurrences $(22 \%)$, negatively influencing cancer-specific survival rate. A more individualized, tumor-specific, and biologically oriented therapy $[25,26]$ would be needed to improve survival probability in the future.

\section{Acknowledgements}

We acknowledge the support of Hanna Rapp, MD, for collection of missing and follow-up clinical data from part of the medical region. The oncology nurses Berit Bermark and Helené Johansson also took part in data collection.

\section{Disclosure}

The authors report no conflict of interest.

\section{References}

1. Bray F, Ferlay J, Soerjomataram I et al. Global cancer statistics 2018: GLOBOCAN estimates of incidence and mortality worldwide for 36 cancers in 185 countries. CA Cancer I Clin 2018; 68: 394-424.

2. Marth C, Landoni F, Mahner S et al. Cervical cancer: ESMO Clinical Practice Guidelines for diagnosis, treatment and follow-up. Ann Oncol 2017; 28 (suppl 4): iv72-iv83.

3. Vaccarella S, Franceschi S, Engholm G et al. 50 years of screening in the Nordic countries: quantifying the effects on cervical cancer incidence. Br J Cancer 2014; 111: 965-969.

4. Green JA, Kirwan JM, Tierney JF et al. Survival and recurrence after concomitant chemotherapy and radiotherapy for cancer of the uterine cervix: a systematic review and meta-analysis. Lancet 2001; 358: 781-786.

5. Thomas GM. Improved treatment for cervical cancer - concurrent chemotherapy and radiotherapy. N Engl J Med 1999; 340: 1198-1200.

6. Rose PG, Ali S, Watkins E et al. Long-term follow-up of a randomized trial comparing concurrent single agent cisplatin, cisplatin-based combination chemotherapy, or hydroxyurea during pelvic irradiation for locally advanced cervical cancer: a Gynecologic Oncology Group Study. J Clin Oncol 2007; 25: 2804-2810.

7. Haie-Meder C, Pötter R, van Limbergen E et al. Recommendations from Gynaecological (GYN) GEC-ESTRO Working Group (I): concepts and terms in 3D image based 3D treatment planning in cervix cancer brachytherapy with emphasis on MRI assessment of GTV and CTV. Radiother Oncol 2005; 74: 235-245.

8. Sturdza A, Pötter R, Fokdal LU et al. Image guided brachytherapy in locally advanced cervical cancer: Improved pelvic control and survival in RetroEMBRACE, a multicenter cohort study. Radiother Oncol 2016; 120: 428-433.

9. Karlsson J, Dreifaldt AC, Mordhorst LB et al. Differences in outcome for cervical cancer patients treated with or without brachytherapy. Brachytherapy 2017; 16: 133-140.

10. Fokdal L, Sturdza A, Mazeron R et al. Image guided adaptive brachytherapy with combined intracavitary and interstitial technique improves the therapeutic ratio in locally advanced cervical cancer: Analysis from the retroEMBRACE study. Radiother Oncol 2016; 120: 434-440.

11. Bohr Mordhorst L, Karlsson L, Barmark B et al. Combined external and intracavitary irradiation in treatment of advanced cervical carcinomas: predictive factors for treatment outcome and early and late radiation reactions. Int J Gynecol Cancer 2014; 24: 1268-1275.

12. Nesvacil N, Tanderup K, Lindegaard JC et al. Can reduction of uncertainties in cervix cancer brachytherapy potentially improve clinical outcome? Radiother Oncol 2016; 120: 390-396.

13. Auth B. Therapy evaluation program, common terminology criteria for adverse events, version 3.0. DCTD, NCI, NIH, DHMS: 2003 (http:/ / ctep.cancer.gov), publish date: August 9, 2006.

14. Yang J, Cai H, Xiao ZX et al. Effect of radiotherapy on the survival of cervical cancer patients. An analysis based on SEER database. Medicine 2019; 98: e16421.

15. Perez CA, Grigsby PW, Chao KS et al. Tumor size, irradiation dose, and long-term outcome of carcinoma of uterine cervix. Int J Radiat Oncol Biol Phys 1998; 41: 307-317. 
16. Vale C, Thierny JF, Stewart LA. Reducing uncertainties about the effects of chemoradiotherapy for cervical cancer: a systematic review and meta-analysis of individual patient data from 18 randomized trials. J Clin Oncol 2008; 26: 5802-5812.

17. Sorbe B, Bohr L, Karlsson L et al. Combined external and intracavitary irradiation in treatment of advanced cervical carcinomas: predictive factors for local tumor control and early recurrences. Int J Oncol 2010; 36: 371-378.

18. Rijkmans EC, Nout RA, Rutten IHHM et al. Improved survival of patients with cervical cancer treated with image-guided brachytherapy compared with conventional brachytherapy. Gynecol Oncol 2014; 135: 231-238.

19. Tanderup K, Lindegaard JC, Kirisits C et al. Image guided adaptive brachytherapy in cervix cancer: A new paradigm changing clinical practice and outcome. Radiother Oncol 2016; 120: 365-369.

20. Pötter R, Tanderup K, Kirisits $C$ et al. The EMBRACE II study: The outcome and prospect of two decades of evolution within the GEC-ESTRO GYN working group and the EMBRACE studies. Clin Transl Radiat Oncol 2018; 9: 48-60.

21. Schmid MP, Franckena M, Kirchheiner K et al. Distant metastasis in patients with cervical cancer after primary radiotherapy with or without chemotherapy and image guided adaptiv brachytherapy. Gynecol Oncol 2014; 133: 256-262.

22. Mazeron R, Fokdal LU, Kirchheiner K et al. Dose-volume effect relationships for late rectal morbidity in patients treated with chemoradiation and MRI-guided adaptive brachytherapy for locally advanced cervical cancer: Results from the prospective multicenter EMBRACE study. Radiother Oncol 2016; 120: 412-419.

23. Mahantshetty U, Sturdza A, Naga CH P et al. Vienna-II ring applicator for distal parametrial/pelvic wall disease in cervical cancer brachytherapy: An experience from two institutions: Clinical feasibility and outcome. Radiother Oncol 2019; 141: 123-129.

24. Walter F, Maihöfer C, Schüttrumpf L et al. Combined intracavitary and interstitial brachytherapy of cervical cancer using the novel hybrid applicator Venezia: Clinical feasibility and initial results. Brachytherapy 2018; 17: 775-781.

25. Tewari KS, Sill MW, Long 3rd HJ et al. Improved survival with bevacizumab in advanced cervical cancer. $N$ Engl J Med 2014; 370: 734-743.

26. Zammataro L, Lopez S, Bellone $S$ et al. Whole-exome sequencing of cervical carcinomas identifies activating ERBB2 and PIK3CA mutations as targets for combination therapy. Proc Natl Acad Sci U S A 2019; 116: 22730-22736. 